\title{
Pyramid-like Gold Electrodeposit Formation in the Stranski- Krastanov Mode
}

\author{
M. Saitou \\ Department of Mechanical Systems Engineering, University of the Ryukyus, 1 Senbaru Nishihara-cho \\ Okinawa, 903-0213, Japan \\ E-mail: saitou@tec.u-ryukyu.ac.jp
}

doi: $10.20964 / 2017.04 .08$

Received: 10 January 2017 / Accepted: 8 February 2017 / Published: 12 March 2017

The Sranski-Krastanov ( $\mathrm{S}-\mathrm{K}$ ) mode transition in gold electrodeposition using a sodium disulfitoaurate (I) solution was investigated. After a smooth gold thin film was grown on an Indium Tin Oxide (ITO) glass, a pyramid-like gold electrodeposit emerged on the smooth gold thin film. The pyramid-like gold electrodeposit showed a truncated pyramid-like configuration comprising four (111) planes. A critical film thickness at which the pyramid-like gold electrodeposit appears was found to be dependent on temperature. Texture coefficients of the gold thin film determined by $\mathrm{x}$-ray diffraction (XRD) reveal that the S-K mode transition takes place when the (110) plane becomes dominant among the other crystallographic planes such as the (111), the (100), and the (311) plane. A scanning electron microscope (SEM) image shows that the pyramid-like gold electrodeposit formed at the critical film thickness may become a candidate for quantum dots.

Keywords: Stranski-Krastanov mode, pyramid-like gold electrodeposit, critical film thickness, texture coefficient, sodium disulfitoaurate (I)

\section{$\underline{\text { FULL TEXT }}$}

(C) 2017 The Authors. Published by ESG (www.electrochemsci.org). This article is an open access article distributed under the terms and conditions of the Creative Commons Attribution license (http://creativecommons.org/licenses/by/4.0/). 